\title{
Novel Materials Synthesized from Red Mud, Bagasse, and Bentonite for Gas Treatment by $\mathrm{CO}_{2}$ Absorption
}

\author{
Nguyen Hoc Thang ${ }^{1, a}$, Nguyen Hoang Luong Ngoc $^{1}$, Vo Thi Nha Uyen ${ }^{1}$ and Pham Trung Kien ${ }^{2}$ \\ ${ }^{1}$ Faculty of Chemical Technology, Ho Chi Minh City University of Food Industry, Ho Chi Minh City, Viet Nam \\ ${ }^{2}$ Faculty of Materials Technology, Ho Chi Minh City University of Technology, Ho Chi Minh City, Viet Nam
}

\begin{abstract}
Carbon dioxide $\left(\mathrm{CO}_{2}\right)$ is a gas which causes both impact to atmosphere (one of greenhouse gases) and decrease heating value of gaseous fuel (such as natural gas, biogas, landfill and sewage gas). Hence, there are many investigations to find solutions for gas treatment and carbon dioxide absorption from researchers. Catalyst or synthesized materials is to optimize processes of $\mathrm{CO}_{2}$ treatment and absorption to obtain the best benefit for factories and community. This study utilized industrial wastes of red mud and bagasse in combination with bentonite to synthesis the novel material (absorbent) responding requirements for the process of gas treatment. More specially, raw materials are impacting negatively on the environment. In which, red mud is solid waste of Bayer process from bauxite mining which is being the hard problem to have solutions for its management and utilization and bagasse is industrial waste of sugar factories. Wet pressing method was applied to form the absorbent samples by mixing red mud, bagasse, bentonite, and water in mixtures. The samples were put in furnace for heating process at $300^{\circ} \mathrm{C}$ for 2 hours. The final samples were characterized for microstructure using X-ray diffraction (XRD) and fourier transform infrared spectroscopy (FTIR). And then the absorbents were tested for gas absorption capacity of carbon dioxide. The results showed a potential application of the novel absorbent materials for gas treatment.
\end{abstract}

\section{Introduction}

Development of industries helped human control everything and produce many convenient products for life. However, the process also caused many problems impact negatively to environment, ecological system, and community. For examples, Bauxite mining industry produced aluminum (Al), aluminum oxide $\left(\mathrm{Al}_{2} \mathrm{O}_{3}\right)$, aluminum hydroxide $\left(\mathrm{Al}\left(\mathrm{OH}_{3}\right)\right)$ to supply for other fields but the Bayer process discharged a large of red mud (RM) amount. RM or red sludge can cause risks such as impacts to the environment of high alkaline ( $\mathrm{pH} \mathrm{10-13),}$ RM particles are fine which caused silicosis disease, potential dangers from RM dams, e.g... The annual amount of RM is estimated of 2.7 billion tonnes all over the world and around one million tonnes in Viet Nam (these amounts are continuing to grow up on the project of bauxite exploitation and processing of alumina production). Therefore, the management and utilization of RM waste are necessary requirements for researchers and managers [1]. Several studies have reported the reuse of red mud in another industry such as for pigment [2] and fillers in polymer materials, among others [3-8]. Recently, there also have been growing interests of using red mud as a raw material for building materials [8-11].

Sugarcane is widely grown in tropical countries to supply raw material resource for sugar industry and others. Sugarcane is a grass group which has height from
3 to 4 meters, diameter about $5 \mathrm{~cm}$. The mature cane at harvest stage contains $12-16 \%$ soluble sugars, $2-3 \%$ nonsugars, $63-73 \%$ water, and $11-16 \%$ fiber [12]. According to the Viet Nam Sugar Association (VSSA), anually, the sugar factories use more than 15 million tons of sugarcane, discharge around 4.5 million tonnes of bagasse. Therefore, the bagasse must be managed and reused to avoid effected to environment and other production activities. The bagasse can be used as organic fuel for biomass process, furnace, and boiler power generation. However, these processes discharged cacbon dioxide which caused impacts to atmosphere and decrease calorific value of gaseous fuels.

There have been investigations for absorption of $\mathrm{CO}_{2}$ using zeolites or activated carbon. At the levels discussed here, $\mathrm{CO}_{2}$ is not toxic and one should not confuse it with the highly toxic carbon monoxide. On the contrary, $\mathrm{CO}_{2}$ increases plant growth as it provides, together with water, the basic materials needed for photosynthesis. The principal risk of an increase in atmospheric $\mathrm{CO}_{2-}$ concentration IS its impact on the radiation balance of the atmosphere, the so-called greenhouse effect. For biogas or natural gas, carbon dioxide is chemically inert in nature and slightly heavier than air. It has high specific heat capacity and does not support combustion. Methane is known to be the main constituent gaseous fuel (such as natural gas, biogas, landfill and sewage gas) that contributes to the heating value of fuels. The presence of

\footnotetext{
$\overline{{ }^{a} \text { Corresponding author: thangnh@ }}$ cntp.edu.vn
} 
high amounts of carbon dioxide in a mixture of natural gas/carbon dioxide can cause a lower heating value of the mixture when compared with pure natural gas. This, in turn, leads to a reduction in the burning velocity which ultimately affects the performance of the engine [13].

\section{Methodology}

\subsection{Synthesis of Absorbent Materials from Red Mud, Bagasse, and Bentonite.}

Raw materials (red mud, bagasse, and bentonite) were prepared in particle size distribution less than $90 \mu \mathrm{m}$ using ball miller and $90 \mu \mathrm{m}$-siever, and then dried at $110^{\circ} \mathrm{C}$ for 24 hours. The materials were tested physico-chemical and microstructural properties before mixed together to synthesis the absorbent. The mixtures had the ratio of RM, $\mathrm{BG}$, and Bentonite as listed in the following table:

Table 1. Mix propotions (\%, in weight) of the gas absorption materials only.

\begin{tabular}{|c|c|c|c|}
\hline Mix & RM & BG & Bentonite \\
\hline Mix 613 & 60 & 10 & 30 \\
\hline Mix 523 & 50 & 20 & 30 \\
\hline Mix 433 & 40 & 30 & 30 \\
\hline
\end{tabular}

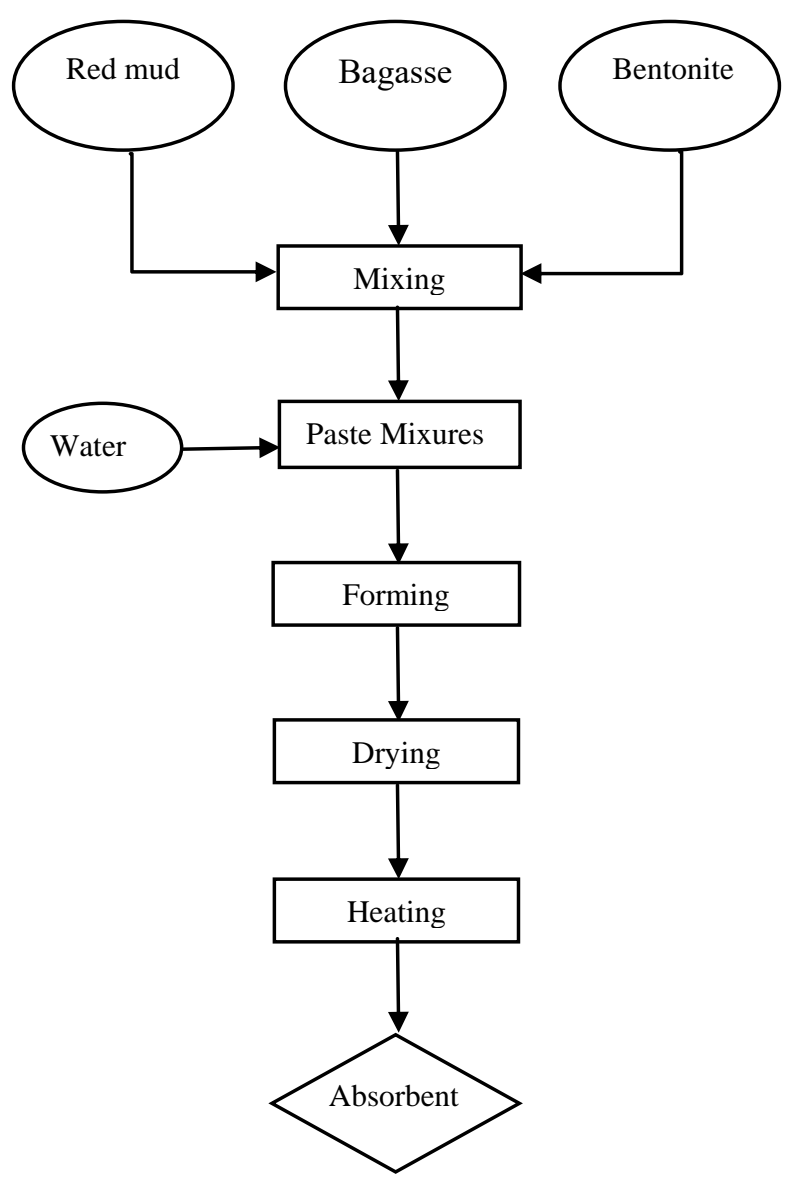

Figure 1. Experimental diagram for production of absorbents
Water was added the mixtures with $40 \%$ (liquid per solid phase in weight) to form the samples by wet-press process. All samples were dried at room condition $\left(30^{\circ} \mathrm{C}\right.$, $80 \%$ humidity) and then heated at $300^{\circ} \mathrm{C}$ for 2 hours. The experimental processes are shown in Fig.1. Finally, the absorbent materials were tested for phase structure using $\mathrm{X}$-ray diffraction and absorption capacity of $\mathrm{CO}_{2}$ gas.

\subsection{Testing Technique of $\mathrm{CO}_{2}$ Absorption.}

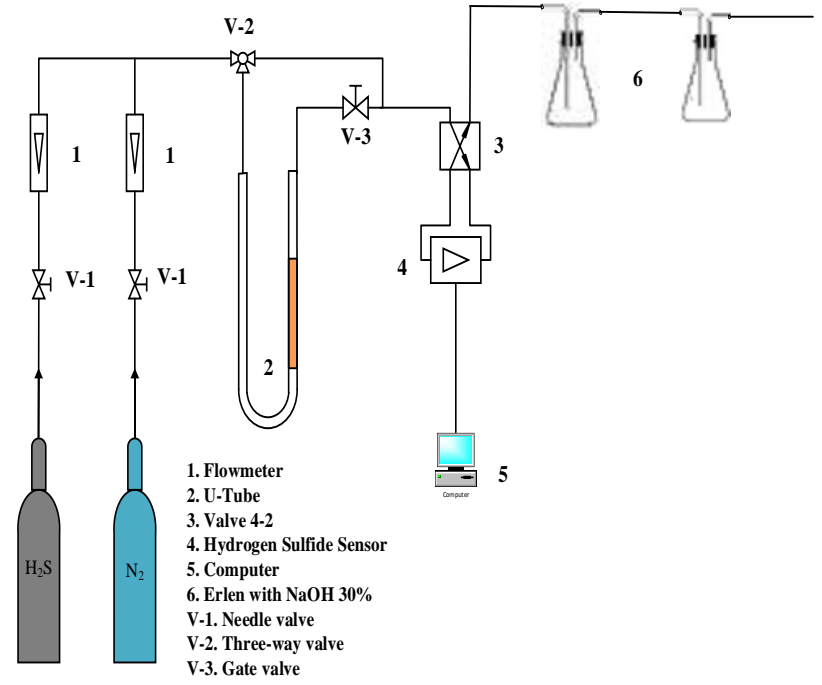

Figure 2. Diagram of $\mathrm{CO}_{2}$ adsorption system [14].

Fig. 2 shows a system which was used to test for carbon dioxide absorption of the materials synthesized from red mud, bagasse, and bentonite. In this diagram, the main system included two tanks of $\mathrm{N}_{2}$ and $\mathrm{CO}_{2}$. The adsorption process was conducted at room condition $\left(30^{\circ} \mathrm{C}, 1 \mathrm{~atm}\right)$. Flowmeter (No. 1) is used to adjust with fixed flow at 3 $\mathrm{L} / \mathrm{h}$. The initial concentration of $\mathrm{CO}_{2}$ gas in the mixture was fixed at $1000 \mathrm{ppm}$. The synthesized material (absorbent) from red mud and bagasse/ bentonite was contained in the reaction tube of U-shaped Pyrex $(0.8 \mathrm{~cm}$ in diameter and $25 \mathrm{~cm}$ in height) with the mass was a range of $0.18-0.19$ gram. At input, flow of gas mixture was led into the reaction tube absorbed by the absorbent, and then at output, the concentration of $\mathrm{CO}_{2}$ gas was measured and recorded continuously by the probe sensor [14].

Based on the adsorption graphs obtained from the computer, the degree of absorbent for the $\mathrm{CO}_{2}$ gas can be determined by the equation:

$$
C_{\text {cap }}=\frac{M_{C} \times 10^{-3}}{m_{\text {absorbent }}} \times \frac{P}{R T} \times F \int\left(C_{\text {in }}-C_{\text {out }}\right) d t \quad(\mathrm{mgC} / \mathrm{g})
$$

In which:

$\mathrm{M}_{\mathrm{C}}=12(\mathrm{~g} / \mathrm{mole})$ molecular weight of carbon.

$\mathrm{m}_{\text {absorbent }}(\mathrm{g})$ weight of absorbent used to absorb $\mathrm{CO}_{2}$ gas.

$\mathrm{P}=1$ (atm) pressure during $\mathrm{CO}_{2}$ adsorption.

$\mathrm{T}=303(\mathrm{~K})$ temperature at the time for testing $\mathrm{CO}_{2}$ adsorption.

$\mathrm{R}=0.082$ (L.atm/mol.K) the ideal gas constant.

$\mathrm{C}_{\mathrm{in}}$ (ppm): input concentration of $\mathrm{CO}_{2}$ in the gas mixture. 
$\mathrm{C}_{\text {out }}(\mathrm{ppm})$ : concentration of $\mathrm{CO}_{2}$ at the point of breakthrough.

$\mathrm{F}(\mathrm{L} / \mathrm{h})$ : flow of input gas.

$\mathrm{t}$ (h): time to reach breakthrough levels.

\section{Results and Discussion}

The results of XRD analysis showed the absorbents have the same structure with high amorphous phases because of broad and noise of XRD backgrounds. There are also peaks with high intensity were detected. They are crystal structures of alumina $\left(\mathrm{Al}_{2} \mathrm{O}_{3}\right)$, hematite $\left(\mathrm{Fe}_{2} \mathrm{O}_{3}\right)$, and quartz $\left(\mathrm{SiO}_{2}\right)$ as shown in Fig. 3.

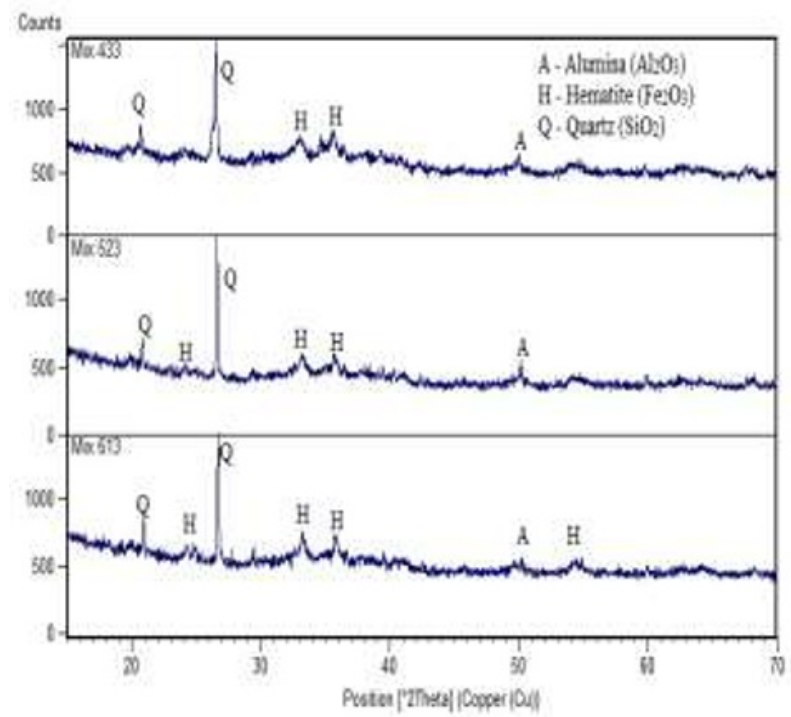

Figure 3. XRD patterns of absorbents (mix 433, 523, and 613).

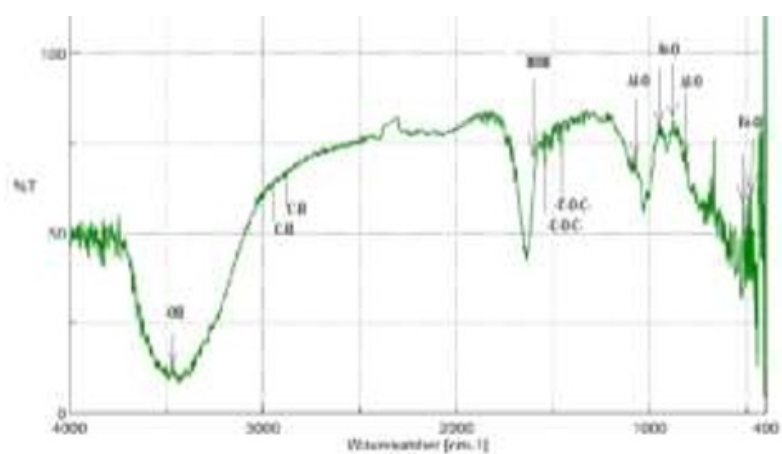

Figure 4. FTIR spectrum of absorbent (mix 433).

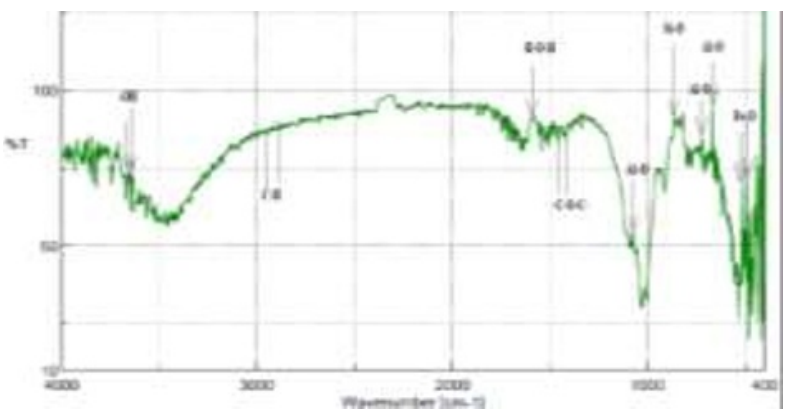

Figure 5. FTIR spectrum of absorbents (mix 523).

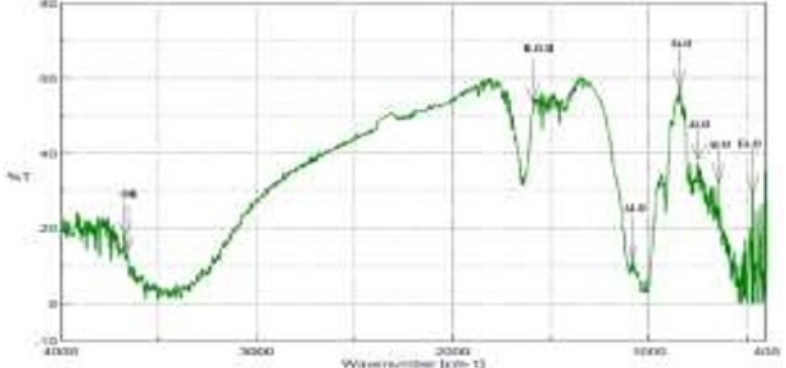

Figure 6. FTIR spectrum of absorbents (mix 613).

The results of FTIR analysis showed the absorbents have the structures in bondings of Si-O, Al-O, Fe-O, C-H, O-H, and others. These groups are characterized by vibrational wavenumber such as $3000,3800,1700,1650,1030,1020$, $1000,950,820,780,680,450\left(\mathrm{~cm}^{-1}\right)$ as shown in Fig. $4,5,6$.

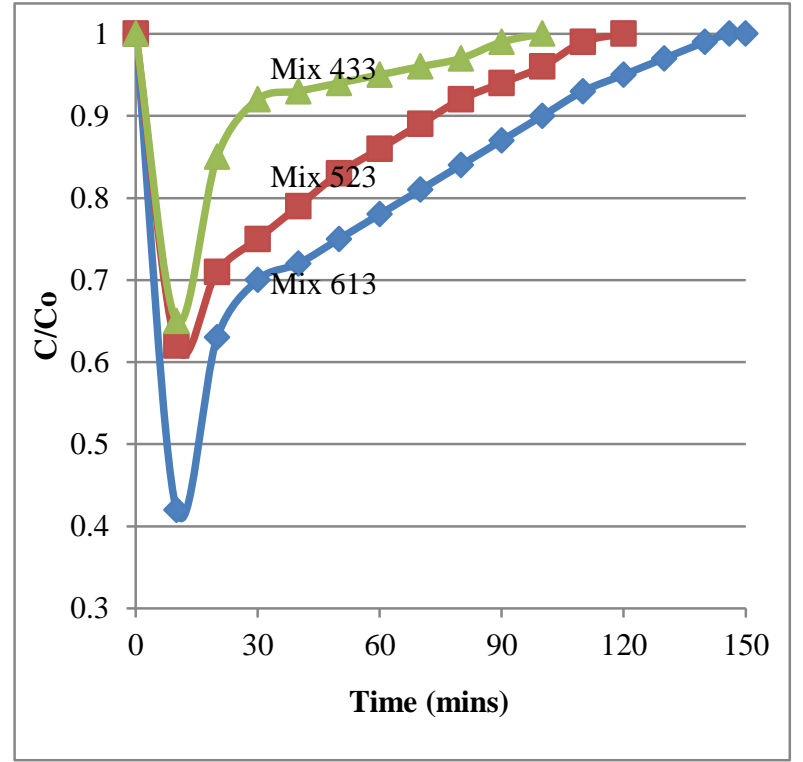

Figure 7. Absorption capacity of absorbents with $\mathrm{CO}_{2}$ gas.

Table 2. Input and output parameters for $\mathrm{CO}_{2}$ absorption processes of absorbents.

\begin{tabular}{|c|c|c|c|}
\hline \multirow{2}{*}{ Parameters } & \multicolumn{3}{|c|}{ Samples } \\
\cline { 2 - 4 } & Mix 613 & Mix 523 & Mix 433 \\
\hline $\begin{array}{c}\text { Capacity } \\
\text { [mgC/g] }\end{array}$ & 157.27 & 180.64 & 125.37 \\
\hline Max [ppm] & 1021.00 & 1208.00 & 1023.00 \\
\hline Min [ppm] & 301.80 & 341.60 & 206.60 \\
\hline $\begin{array}{c}\text { Flow of input } \\
\text { gas [L/h] }\end{array}$ & 3.00 & 3.00 & 3.00 \\
\hline $\begin{array}{c}\text { Time of } \\
\text { absorption } \\
\text { [mins] }\end{array}$ & 125 & 146 & 96 \\
\hline $\begin{array}{c}\text { Weight of } \\
\text { absorbent [g] }\end{array}$ & 0.1827 & 0.1826 & 0.1831 \\
\hline
\end{tabular}


The experimental data show that the values of $\mathrm{CO}_{2}$ absorption capacity are in range of 125.37-180.64 $(\mathrm{mgC} / \mathrm{g})$. In which, the sample with $20 \% \mathrm{BG}$ and $50 \%$ RM (Mix 523) has the highest value of the capacity at $180.64(\mathrm{mgC} / \mathrm{g})$. This sample also has the longest time of absorption at 146 minutes in comparison with the others. Because the process of combustion burned the BG caused increase porosity and concentration of charcoal in the absorbents. Both two factors (porosity and concentration of charcoal) are as main role effect to the absorption capacity of $\mathrm{CO}_{2}$ gas. In comparison with other studies using red mud and/or bagasse to syntheses absorbents, the values obtained in this research are better when evaluated in the same conditions in recent years.

\section{Conclusions}

This study proposes a method to utilize red mud (Bauxite mining industry) and bagasse (sugar production process from sugarcane) as raw materials for synthesizing the absorbents in combination with bentonite. The results showed that the materials have amorphous and crystal phases in the structures. Using the $\mathrm{CO}_{2}$ adsorption system and the equation for determination of absorption capacity, the absorbents have high capacity at $180.64 \mathrm{mgC} / \mathrm{g}$ for 146 minutes. The values are better than other research using red mud and bagasse. Further researches will be carried out for optimization of mix design among raw materials as well as evaluation effect of heat treatment to absorption capacity of $\mathrm{CO}_{2}$ and others gas. Analysis of microstructures and surface area of absorbents will be conducted using BET, FTIR, and SEM for explanation of the experimental data.

\section{References}

1. H.T. Nguyen, T.K.A. Le, N.H. Nguyen, Q.L. Nguyen, T.K. Pham, M.A.B. Promentilla, 23rd Regional Symposium on Chemical Engineering (RSCE2016) (2016)

2. S. Chandra, Waste materials used in concrete manufacturing, Noyes, USA, (1997)

3. S.S. Amritphale, A. Anshul, N. Chandra, N. Ramakrishnan, Journal of the European Ceramic Society 27 (2007)

4. S. Ordonez, H. Sastre, F.V. Diez, Journal of Hazard Materials B81 (2001)

5. S. Shushil and V.S. Batra, Applied Catalysis B: Environmental 81 (2008)

6. H.T. Nguyen, V.T.H.Q. Pham, T.P. Dang, and T.K. Dao, AIP Conference Proceedings 1954:1 (2018)

7. A.K.R. Sumabat, A.J. Manalac, H.T. Nguyen, M.E. Kalaw, R.R. Tan, M.A.B. Promentilla, Chemical Engineering Transaction 45 (2015)

8. H.T. Nguyen, T.N. Le, V.T.H.Q. Pham, T.P. Dang, T.K. Dao, and V.P. Nguyen, AIP Conference Proceedings 1954:1 (2018)

9. M.A.B. Promentilla, H.T. Nguyen, T.K. Pham, H.Hinode, F.T. Bacani, S.M. Gallardo, Waste biomass valorize 7 (2016)
10. H.T. Nguyen, T.K. Pham, M.M.A.B. Abdullah, MATEC Web Conference 97 (2017)

11. M.A.B. Promentilla, M.E. Kalaw, H.T. Nguyen, K.B. Aviso, R.R. Tan, Computer Aided Chemical Engineering 40 (2017)

12. R. Perez, Feeding pigs in the tropics, Food and Agriculture Organization of the United Nations, (1997)

13. S. Bari, Renewab. Energy 9 (1996)

14. H.T. Nguyen, V.T.H.Q. Pham, T.N. Le, T.P. Dang, and N.K.T. Nguyen, AIP Conference Proceedings 1954:1 (2018) 